\title{
The effect of displacement damage on deuterium retention in ITER-grade $W$ exposed to low-energy, high-flux pure and helium-seeded deuterium plasmas
}

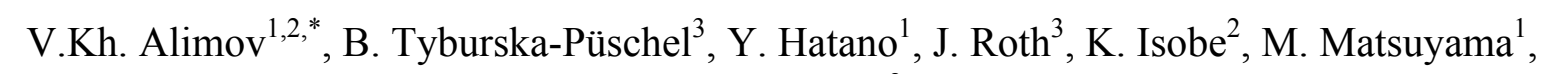
T. Yamanishi ${ }^{2}$

\author{
${ }^{1}$ Hydrogen Isotope Research Center, University of Toyama, Toyama 930-8555, Japan \\ ${ }^{2}$ Tritium Technology Group, Japan Atomic Energy Agency, Tokai, Ibaraki 319-1195, Japan \\ ${ }^{3}$ Max-Planck-Institut für Plasmaphysik, EURATOM Association, D-85748 Garching, Germany
}

\begin{abstract}
Samples prepared from polycrystalline ITER-grade tungsten were damaged by irradiation with $20 \mathrm{MeV} \mathrm{W}$ ions at room temperature to a fluence of $1.4 \times 10^{18} \mathrm{~W} / \mathrm{m}^{2}$. Due to the irradiation, displacement damage peaked near the end-of-range, $1.35 \mu \mathrm{m}$ beneath the surface, at 0.89 displacements per atom. The damaged as well as undamaged $\mathrm{W}$ samples were then exposed to low-energy, high-flux $\left(10^{22} \mathrm{D} / \mathrm{m}^{2} \mathrm{~s}\right)$ pure $\mathrm{D}$ and helium-seeded $\mathrm{D}$ plasmas to an ion fluence of $3 \times 10^{26} \mathrm{D} / \mathrm{m}^{2}$ at various temperatures. Trapping of deuterium was examined by the $\mathrm{D}\left({ }^{3} \mathrm{He}, \mathrm{p}\right){ }^{4} \mathrm{He}$ nuclear reaction at ${ }^{3} \mathrm{He}$ energies varied from 0.69 to $4.0 \mathrm{MeV}$ allowing determination of the D concentration at depths up to $6 \mu \mathrm{m}$. It has been found that (i) addition of $5 \%$ helium ions into the D plasma at exposure temperatures of $440-650 \mathrm{~K}$ significantly reduces the $\mathrm{D}$ concentration at depths of 0.5-6 $\mu \mathrm{m}$ compared to that for the pure plasma exposure; (ii) generation of the W-ioninduced displacement damage significantly increases the D concentration at depths up to $2 \mu \mathrm{m}$ (i.e., in the damage zone) under following exposure both to the pure D and D-He plasmas.
\end{abstract}

*Corresponding author. Tel.:+81 76445 6934; fax: +81 764456931.

E-mail address: alimov@ctg.u-toyama.ac.jp (V.Kh. Alimov). 


\section{Introduction}

Due to its favorable physical properties, such as low erosion yield and high melting temperature, tungsten (W) is employed as a candidate material for plasma-facing high heat-flux structures in future fusion reactors. As plasma-facing material in the fusion reactors, $\mathrm{W}$ will be subject to intensive fluxes of energetic deuterium (D) and tritium (T) particles as well as helium (He) ions and $14 \mathrm{MeV}$ neutrons (n) from the $\mathrm{D}-\mathrm{T}$ fusion reaction. Neutron irradiation causes modification of the $\mathrm{W}$ crystal structure and creates displacements in the bulk [1,2]. These processes lead to concerns about tritium inventory in the n-irradiated W after long-term deuterium-tritium plasma exposure. One of the ways to investigate the influence of n-produced defects on the hydrogen isotope inventory is to simulate displacement damage in tungsten using irradiation with energetic ions. It has been shown that defects produced by irradiation with $\mathrm{H}, \mathrm{Si}$, and $\mathrm{W}$ ions enhance deuterium retention in $\mathrm{W}$ materials after subsequent irradiation with $\mathrm{D}$ ions or exposure to D plasmas [3, 4, 5, 6, 7, 8,9].

Seeding of He ions into the D plasma significantly reduces the $\mathrm{D}$ retention at elevated temperatures in undamaged $\mathrm{W}$ materials $[10,11,12,13]$. Dynamic nano-scale helium bubble formation and development of an open porosity in the near-surface layer create short-circuit paths to the surface thus enhancing the D re-emission and limiting the D diffusion into the bulk $[11,14]$. He co-implantation reduces D inward diffusion when the He implantation range is similar to or greater than that of D [15].

There are only few publications reporting on deuterium trapping at displacement damage in tungsten, namely in hot-rolled $\mathrm{W}$ foils, exposed to He-seeded deuterium plasma [4, 8]. The objective of this work are comparison studies of D retention at displacement damage in ITERgrade $\mathrm{W}$ exposed to pure and He-seeded D plasmas at elevated temperatures ( $\geq 440 \mathrm{~K}$ ).

\section{Experimental}

Polycrystalline ITER-grade W delivered from A.L.M.T. Corp. (Japan) has a purity of 99.99 wt.\% with main impurities being Mo, Fe, C and O. The ITER-grade W is deformed (rolled, swaged and/or forged) followed by appropriate heat-treatments to obtain better mechanical properties, e.g., strength and toughness, after the sintering process [16, 17]. In consequence, the microstructure of the ITER-grade W consists of anisotropically elongated grains along the deformation axis [18]. The grain size is $1-3 \mu \mathrm{m}$ in section and up to $5 \mu \mathrm{m}$ in length. Individual elongated cracks observed between grains are due to the deformation treatment. Square-shaped 
samples, $10 \times 10 \mathrm{~mm}^{2}$ in size and $2 \mathrm{~mm}$ in thickness, were so prepared by the manufacturer that the irradiated surfaces were perpendicular to deformation axis (i.e., to the heat transfer direction), which corresponds to the ITER specification. The samples were mechanically polished, clean in the acetone ultrasonic bath, and then annealed in vacuum at $1473 \mathrm{~K}$ for $30 \mathrm{~min}$ for stress relief.

Some of the $\mathrm{W}$ samples were irradiated with $3.33 \mathrm{MeV} \mathrm{W}^{6+}$ ions $(20 \mathrm{MeV} / \mathrm{W})$ to a fluence of $1.4 \times 10^{18} \mathrm{~W} / \mathrm{m}^{2}$ at room temperature. As a result, the near-surface layer of the samples was damaged to 0.89 displacements per atom (dpa) at the damage peak situated at a depth of $1.35 \mu \mathrm{m}$. The damage profile was calculated using the program SRIM 2008.03 [19], "full cascade option", with a displacement energy of $E_{\mathrm{d}}=90 \mathrm{eV}[20,21]$. Hereafter, the W samples irradiated with the $\mathrm{W}$ ions will be designated as damaged ones.

The damaged as well as undamaged $\mathrm{W}$ samples were exposed to low-energy, high-flux pure and helium-seeded deuterium plasmas at elevated temperatures (440-720 K). Note that the damaged samples were exposed to the plasmas on the damaged side. The linear plasma generator used for delivering plasma beams is described in Ref. [22]. To generate a pure D plasma, the $\mathrm{D}_{2}$ working pressure was kept at about $1 \mathrm{~Pa}$. As a result, a plasma beam with species of $\mathrm{D}_{2}{ }^{+}$(over $80 \%$ ) and $\mathrm{D}^{+}$(less than $20 \%$ ) was obtained. A bias voltage of $-80 \mathrm{~V}$ was applied to the $\mathrm{W}$ sample, resulting in incident energy of $76 \mathrm{eV}$ for $\mathrm{D}_{2}{ }^{+}(38 \mathrm{eV} / \mathrm{D})$, taking into account the plasma potential of about $-4 \mathrm{~V}$ as measured by a Langmuir probe. The incident deuterium ion flux and fluence were fixed at $10^{22} \mathrm{D} / \mathrm{m}^{2} \mathrm{~s}$ and $3 \times 10^{26} \mathrm{D} / \mathrm{m}^{2}$, respectively. The sample was passively heated by the plasma itself and the exposure temperature was set by the thermal contact between the sample and the cooled holder. The temperature was monitored using a type $\mathrm{K}$ thermocouple tightly pressed onto the rear of the sample.

To generate a helium-seeded D plasma (D-He plasma), ${ }^{4} \mathrm{He}$ gas was injected into the plasma source region, and the He partial pressure was kept at $10^{-1} \mathrm{~Pa}$. In consequence, the concentration of He ions in the D-He plasma was $10 \%$, which was determined in additional experiments by measuring sputtering yields of a $\mathrm{W}$ target exposed to D-He plasmas with various He percentages [11]. Thus, the ion composition of the D-He plasma was determined to be $\mathrm{D}_{2}{ }^{+}$ $(>72 \%), \mathrm{D}^{+}(<18 \%)$, and $\mathrm{He}^{+}(10 \%)$. Since $\mathrm{D}_{2}{ }^{+}$ions break up into two $\mathrm{D}$ atoms during collisions with the surface $\mathrm{W}$ atoms, the percentage of $\mathrm{He}$ in the flux of penetrating particles is estimated to be about $5 \%$. The samples were exposed to the D-He plasma to a D ion fluence of $3 \times 10^{26} \mathrm{D} / \mathrm{m}^{2}$.

The deuterium profiles in the plasma-exposed $\mathrm{W}$ samples were determined by nuclear reaction analysis (NRA) at IPP, Garching. The $\mathrm{D}\left({ }^{3} \mathrm{He}, \mathrm{p}\right)^{4} \mathrm{He}$ reaction was utilized, and both the $\alpha$ 
particles and protons were analyzed. To determine the D concentration at larger depths, an analyzing beam of ${ }^{3} \mathrm{He}$ ions with energies varied from 0.69 to $4.0 \mathrm{MeV}$ was used. The proton yields measured at different ${ }^{3} \mathrm{He}$ ion energies allow measuring the $\mathrm{D}$ depth profile at depths of up to $6 \mu \mathrm{m}[23]$.

\section{Results}

The deuterium depth profile in the undamaged ITER-grade $\mathrm{W}$ exposed to the pure $\mathrm{D}$ plasma at temperatures $T_{\exp }=460$ and $560 \mathrm{~K}$ is characterized by a concentration of $0.1-0.2$ at.\% at depths of 1-6 $\mu \mathrm{m}$ (in the sub-surface layer). Concentration minima at depths up to $1 \mu \mathrm{m}$ (Fig. 1a) may be connected with the appearance of small blisters and accompanying porosity development [24]. At $T_{\exp }=640 \mathrm{~K}$, the $\mathrm{D}$ concentration in the sub-surface layer does not exceed $10^{-2}$ at.\%. A further increase of the exposure temperature leads to a decrease of the D concentration (Fig. 1a).

Seeding of helium ions into the D plasma at exposure temperatures of $440-650 \mathrm{~K}$ significantly reduces the $\mathrm{D}$ concentration at depths of 0.5-6 $\mu \mathrm{m}$ (Fig. 1b). At $T_{\exp }=440 \mathrm{~K}$, the D concentration is described by a sharp near-surface concentration maximum of about 1 at.\%, and, at depths above $0.5 \mu \mathrm{m}$, by a concentration of about $3 \times 10^{-2}$ at.\% slowly decreasing into the bulk. As the exposure temperature increases up to $650 \mathrm{~K}$, the near-surface $\mathrm{D}$ concentration decreases to about 0.2 at.\%, whereas the sub-surface D concentration becomes below the NRA detection limit $\left(5 \times 10^{-4}\right.$ at.\%) (Fig. 1b).

Generation of ion-induced displacement damage and following exposure both to pure D plasma and D-He plasma significantly increases the D concentration at depths up to $2 \mu \mathrm{m}$ (i.e., in the damage zone) (Fig. 2). However, for all exposure temperatures, the D concentrations at depths of 4-6 $\mu \mathrm{m}$ in the undamaged and damaged $\mathrm{W}$ samples are comparable in a value (Figs. 1 and 2).

The temperature dependence of the total $\mathrm{D}$ retention at depths up to $6 \mu \mathrm{m}$ in the undamaged and damaged ITER-grade $\mathrm{W}$ exposed to the pure deuterium and He-seeded deuterium plasmas is shown in Fig. 3. As illustrated in this Figure, the displacement damage increases significantly the hydrogen isotope retention in the sub-surface layer. 


\section{Discussion}

For tungsten exposed to a high flux D plasma at ion energies well below the displacement threshold, the mechanism of plastic deformation due to deuterium supersaturation [25] is considered to be responsible for the modification of the subsurface structure and formation of trapping sites for deuterium $[26,27]$. As illustrated for the example of recrystallized $\mathrm{W}$ exposed to the D plasma $[28,29]$, intragranular cracks and large cavities at the grain boundaries are formed at depths up to several micrometers. As for the ITER-grade W with the strongly modified grain structure textured perpendicular to the surface, after its exposure to the high-flux D plasma at temperatures in the range from 320 to $600 \mathrm{~K}$, Lindig et al. [24] have only observed blisterassociated cracks elongated in parallel to the surface and localized at depths of several hundreds of nanometers in the near-surface layer strongly distorted by mechanical polishing, without formation of large cavities and extrusions along slip systems like in the recrystallized W, with the exception of solitary cavities formed inside large grains. However, intrinsic intergranular cracks are a feature of the bulk structure of the mechanically-deformed ITER-grade W. These cracks may contribute to the trapping of deuterium in the bulk of the $\mathrm{W}$ material both in the molecular form inside the cracks and as D atoms chemisorbed at the walls of the cracks [18].

Under exposure of the ITER-grade $\mathrm{W}$ to the D-He plasma at elevated temperatures, a dynamic mechanism of nano-scale helium bubble formation [30] can lead to development of an open porosity in the near-surface layer and can create short-circuit paths to the surface thus enhancing the $\mathrm{D}$ re-emission and reducing the flux of $\mathrm{D}$ atoms diffusing into the bulk [31]. As consequence, the D concentration in the bulk of the $\mathrm{W}$ material is significantly lower than that after exposure to the pure D plasma (compare Figs. 1a and 1b).

In the damaged ITER-grade $\mathrm{W}$ exposed to the pure $\mathrm{D}$ and D-He plasmas, the diffusing $\mathrm{D}$ atoms are additionally trapped at the $\mathrm{W}$-ion-induced defects like vacancies and vacancy complexes $[32,33]$ up to concentration higher than that for the undamaged W (Figs. 1 and 2).

Values for the concentration of deuterium at the depth of the damage peak, ${ }^{\text {damage }} C_{\mathrm{D}}$, in the damaged ITER-grade $\mathrm{W}$ exposed to the pure $\mathrm{D}$ and D-He plasmas at various temperatures are shown in Fig. 4 in units of $\mathrm{D}$ to $\mathrm{W}$ atomic ratio. After exposure to the pure $\mathrm{D}$ plasma at temperatures above $450 \mathrm{~K}$, the concentration ${ }^{\text {damage }} C_{\mathrm{D}}$ is always higher than that for the D-He plasma. This observation is in line with reported data [4] on D trapping at displacement damage in hot-rolled $\mathrm{W}$ irradiated with $12 \mathrm{MeV}$ Si ions to $0.6 \mathrm{dpa}$ and then exposed to pure D and D$5 \%$ He plasmas at about $473 \mathrm{~K}$. As the exposure temperature increases, the concentration ${ }^{\text {damage }} C_{\mathrm{D}}$ decreases, both for the pure D plasma and helium-seeded D plasma (Fig. 4). 
Deuterium atoms injected into tungsten from a D plasma quickly reach thermal energies, settle into interstitial solution sites within a few nanometres of the surface, and diffuse through the metal lattice. The concentration of $\mathrm{D}$ in solution near the surface and the flux of $\mathrm{D}$ atoms diffusing into the bulk are governed by the incoming flux of D ions. Seeding of He ions into the D plasma evidently reduces significantly the solute D concentration and flux of diffusing D atoms. Comparing deuterium filling of Si-ion-induced traps in $\mathrm{W}$ exposed to $\mathrm{D}-5 \% \mathrm{He}$ plasma to fluences up to $1.5 \times 10^{26} \mathrm{D} / \mathrm{m}^{2}$ [4] with the present $\mathrm{D}$ ion fluence of $3 \times 10^{26} \mathrm{D} / \mathrm{m}^{2}$, we can state with assurance that the ion-induced defects in the damage zone become fully occupied. Higher concentration of $\mathrm{D}$ trapped in the damage zone observed after exposure to the pure $\mathrm{D}$ plasma (Fig. 4) can be explained by modification of vacancy-type defects. Under exposure to the pure D plasma, high supersaturation solute D concentration maintained in the damage zone is thought to stimulate the growth of the vacancy-type defects thus increasing the retention capacity for D atoms.

\section{Summary}

In polycrystalline ITER-grade $\mathrm{W}$ exposed at 460 and $560 \mathrm{~K}$ to $\mathrm{D}$ plasma $\left(76 \mathrm{eV} \mathrm{D}_{2}^{+}\right)$with high ion flux of $10^{22} \mathrm{D} / \mathrm{m}^{2} \mathrm{~s}$ to a fluence of $3 \times 10^{26} \mathrm{D} / \mathrm{m}^{2}$, deuterium is trapped at intrinsic intergranular cracks and accumulated up to concentration of 0.1-0.2 at.\% within the analyzable depths up to $6 \mu \mathrm{m}$. At exposure temperatures above $560 \mathrm{~K}$, the $\mathrm{D}$ concentration decreases with the temperature and falls to about $10^{-3}$ at. $\%$ at $720 \mathrm{~K}$. Seeding of He ions into the D plasma $\{76$ $\left.\mathrm{eV}\left(\mathrm{D}_{2}^{+}+10 \% \mathrm{He}^{+}\right)\right\}$at elevated temperatures $(440-650 \mathrm{~K})$ significantly reduces the $\mathrm{D}$ concentration at depths of 0.5-6 $\mu \mathrm{m}$.

Displacement damage peaked at $0.89 \mathrm{dpa}$, preliminary generated in the ITER-grade $\mathrm{W}$ by irradiation with $20 \mathrm{MeV} \mathrm{W}$ ions at room temperature, significantly increases retention of deuterium in the damage zone during subsequent exposure the pure D and D-He plasmas. After exposure of the damaged $\mathrm{W}$ to the pure $\mathrm{D}$ plasma, the $\mathrm{D}$ concentration (in units of $\mathrm{D}$ to $\mathrm{W}$ atomic ratio) at a depth of the damage peak, damage $C_{\mathrm{D}}$, decreases with increasing exposure temperature from about $2 \times 10^{-2} \mathrm{D} / \mathrm{W}$ at $T_{\exp }=440 \mathrm{~K}$ to about $2 \times 10^{-3} \mathrm{D} / \mathrm{W}$ at $T_{\exp }=710 \mathrm{~K}$. However, after exposure to the D-He plasma at temperatures above $450 \mathrm{~K}$, the concentration ${ }^{\text {damage }} C_{\mathrm{D}}$ is always lower than that for the pure $\mathrm{D}$ plasma. It is speculated that high supersaturation solute D concentration maintained in the damage zone under exposure to the pure D plasma stimulates the growth of the vacancy-type defects increasing thus the capacity for 
$\mathrm{D}$ atoms. In the case of D-He plasma exposure, the growth of the defects is less significant due to the significantly lower solute D concentration.

\section{Acknowledgements}

The authors would like to thank J. Dorner and M. Fußeder (IPP Garching, Germany) for irradiation of $\mathrm{W}$ samples with $\mathrm{W}$ ions and technical assistance with the ${ }^{3} \mathrm{He}$ beam analyses. 


\section{Figure captions}

Figure 1. Depth profiles of deuterium retained in undamaged polycrystalline ITER-grade W after exposure to pure D plasma $\left(76 \mathrm{eV} \mathrm{D}_{2}^{+}\right)$(a) and D-He plasma $\left\{76 \mathrm{eV}\left(\mathrm{D}_{2}^{+}+10 \% \mathrm{He}^{+}\right)\right\}$(b) with D ion fluence of $3 \times 10^{26} \mathrm{D} / \mathrm{m}^{2}$ at various temperatures.

Figure 2. Depth profiles of deuterium retained in polycrystalline ITER-grade W, damaged to 0.89 dpa by irradiation with $20 \mathrm{MeV} \mathrm{W}$ ions at room temperature, after exposure to pure $\mathrm{D}$ plasma $\left(76 \mathrm{eV} \mathrm{D}_{2}{ }^{+}\right)$(a) and D-He plasma $\left\{76 \mathrm{eV}\left(\mathrm{D}_{2}{ }^{+}+10 \% \mathrm{He}^{+}\right)\right\}$(b) with $\mathrm{D}$ ion fluence of $3 \times 10^{26} \mathrm{D} / \mathrm{m}^{2}$ at various temperatures. In both panels, damage depth profiles are additionally shown, and the damage level scales coincide with the D concentration scales.

Figure 3. Deuterium retention up to $6 \mu \mathrm{m}$ in polycrystalline ITER-grade $\mathrm{W}$, undamaged and damaged to $0.89 \mathrm{dpa}$ by irradiation with $20 \mathrm{MeV} \mathrm{W}$ ions at room temperature, after exposures to pure D plasma $\left(76 \mathrm{eV} \mathrm{D}_{2}{ }^{+}\right)$and D-He plasma $\left\{76 \mathrm{eV}\left(\mathrm{D}_{2}{ }^{+}+10 \% \mathrm{He}^{+}\right)\right\}$with $\mathrm{D}$ ion fluence of $3 \times 10^{26} \mathrm{D} / \mathrm{m}^{2}$, as a function of exposure temperature. The D retention was determined by NRA.

Figure 4. Deuterium concentration (in units of $\mathrm{D}$ to $\mathrm{W}$ atomic ratio) at a depth of the damage peak in damaged ITER-grade $\mathrm{W}$ exposed to pure D plasma $\left(76 \mathrm{eV} \mathrm{D}_{2}{ }^{+}\right)$and D-He plasma $\{76$ $\left.\mathrm{eV}\left(\mathrm{D}_{2}^{+}+10 \% \mathrm{He}^{+}\right)\right\}$, as a function of the exposure temperature. Additionally, data on the D concentration in damaged $\mathrm{W}$ foil exposed to pure $\mathrm{D}$ plasma $\left(76 \mathrm{eV} \mathrm{D}_{2}{ }^{+}\right)$(Tyburska et al. [6]) and damaged hot-rolled $\mathrm{W}$ exposed to pure D plasma $\left(90 \mathrm{eV} \mathrm{D}{ }^{+}\right)$and $\mathrm{D}-\mathrm{He}$ plasma $\left\{90 \mathrm{eV}\left(\mathrm{D}^{+}+5 \%\right.\right.$ $\left.\left.\mathrm{He}^{+}\right)\right\}$(Wampler et al. [4]) are shown for a comparison. The displacement damage characteristics and applied D ion fluences, $\Phi$, are indicated in the legends. 


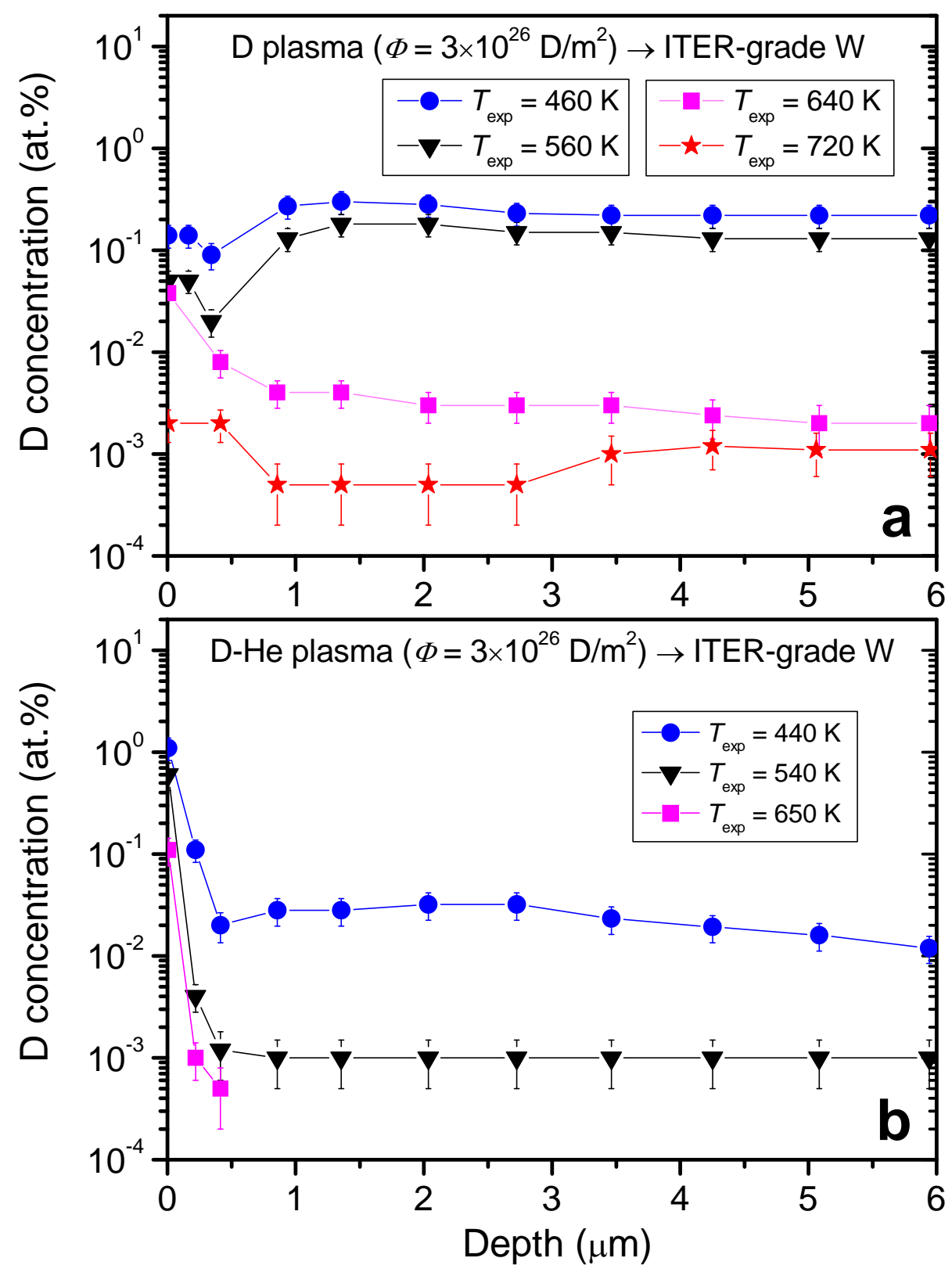

Figure 1. Depth profiles of deuterium retained in undamaged polycrystalline ITER-grade $\mathrm{W}$ after exposure to pure D plasma $\left(76 \mathrm{eV} \mathrm{D}_{2}{ }^{+}\right)$(a) and D-He plasma $\left\{76 \mathrm{eV}\left(\mathrm{D}_{2}^{+}+10 \% \mathrm{He}^{+}\right)\right\}$(b) with $\mathrm{D}$ ion fluence of $3 \times 10^{26} \mathrm{D} / \mathrm{m}^{2}$ at various temperatures. 


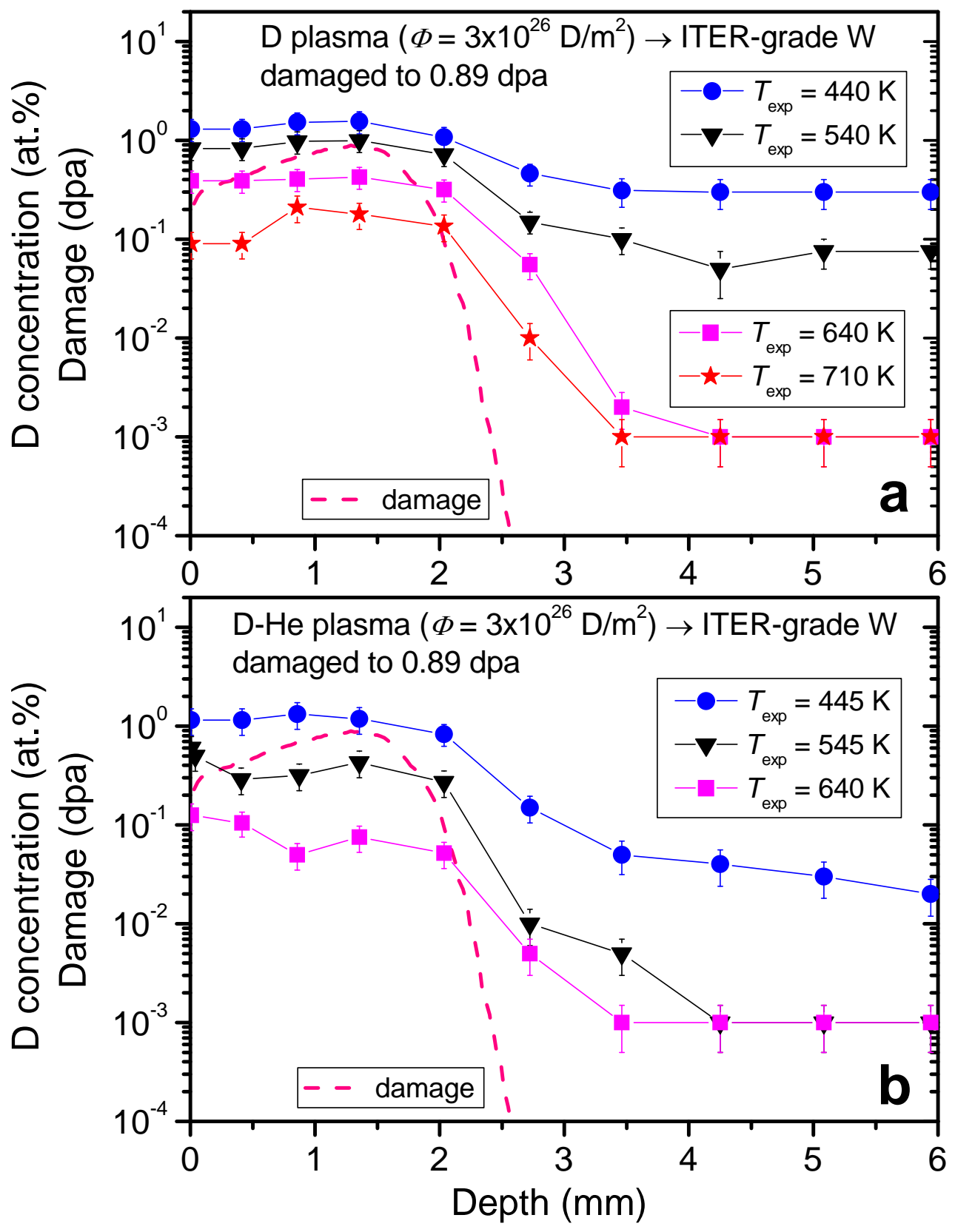

Figure 2. Depth profiles of deuterium retained in polycrystalline ITER-grade W, damaged to 0.89 dpa by irradiation with $20 \mathrm{MeV} \mathrm{W}$ ions at room temperature, after exposure to pure $\mathrm{D}$ plasma $\left(76 \mathrm{eV} \mathrm{D}_{2}^{+}\right)$(a) and D-He plasma $\left\{76 \mathrm{eV}\left(\mathrm{D}_{2}^{+}+10 \% \mathrm{He}^{+}\right)\right\}$(b) with $\mathrm{D}$ ion fluence of $3 \times 10^{26} \mathrm{D} / \mathrm{m}^{2}$ at various temperatures. In both panels, damage depth profiles are additionally shown, and the damage level scales coincide with the D concentration scales. 


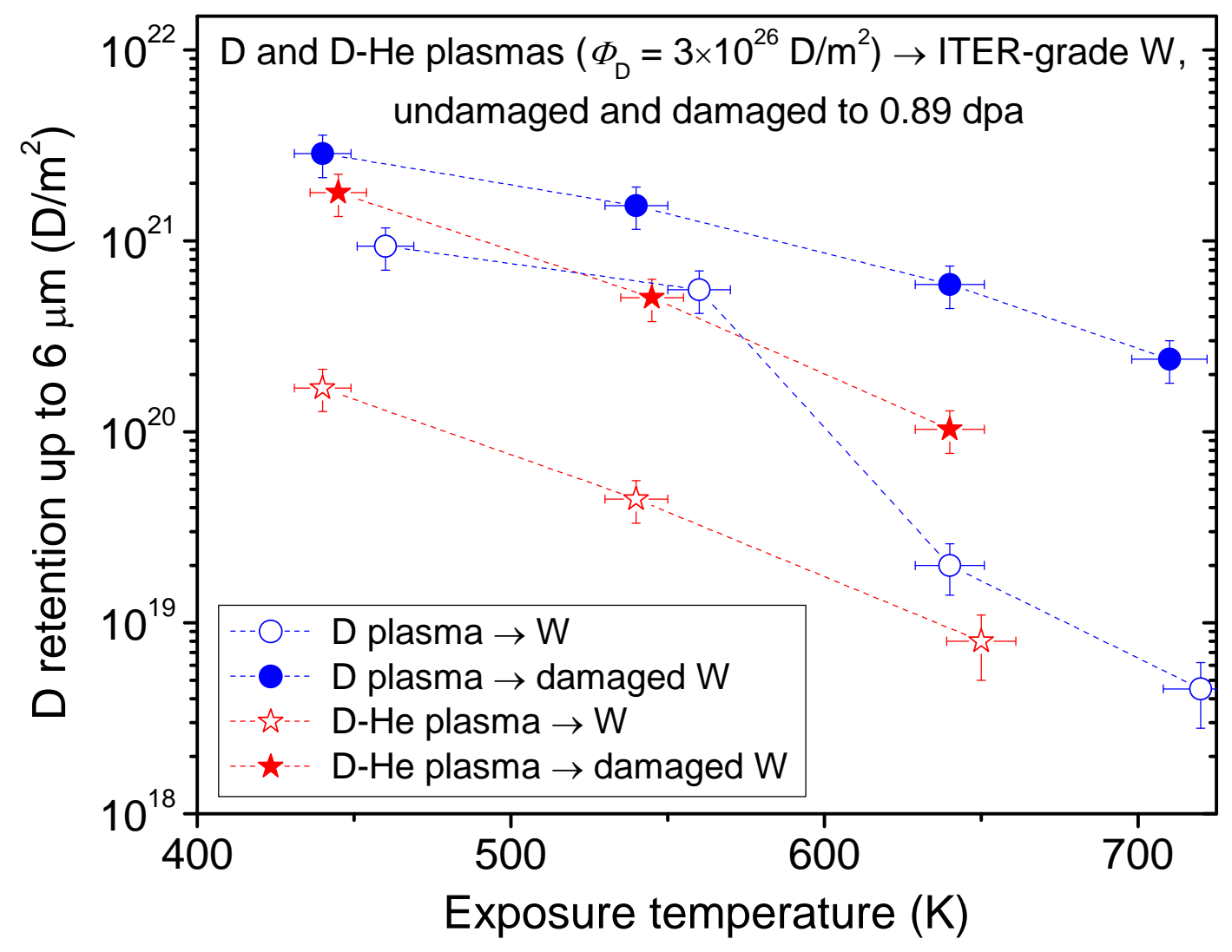

Figure 3. Deuterium retention up to $6 \mu \mathrm{m}$ in polycrystalline ITER-grade $\mathrm{W}$, undamaged and damaged to 0.89 dpa by irradiation with $20 \mathrm{MeV} \mathrm{W}$ ions at room temperature, after exposures to pure D plasma $\left(76 \mathrm{eV} \mathrm{D}_{2}{ }^{+}\right)$and D-He plasma $\left\{76 \mathrm{eV}\left(\mathrm{D}_{2}{ }^{+}+10 \% \mathrm{He}^{+}\right)\right\}$with $\mathrm{D}$ ion fluence of $3 \times 10^{26} \mathrm{D} / \mathrm{m}^{2}$, as a function of exposure temperature. The $\mathrm{D}$ retention was determined by NRA. 


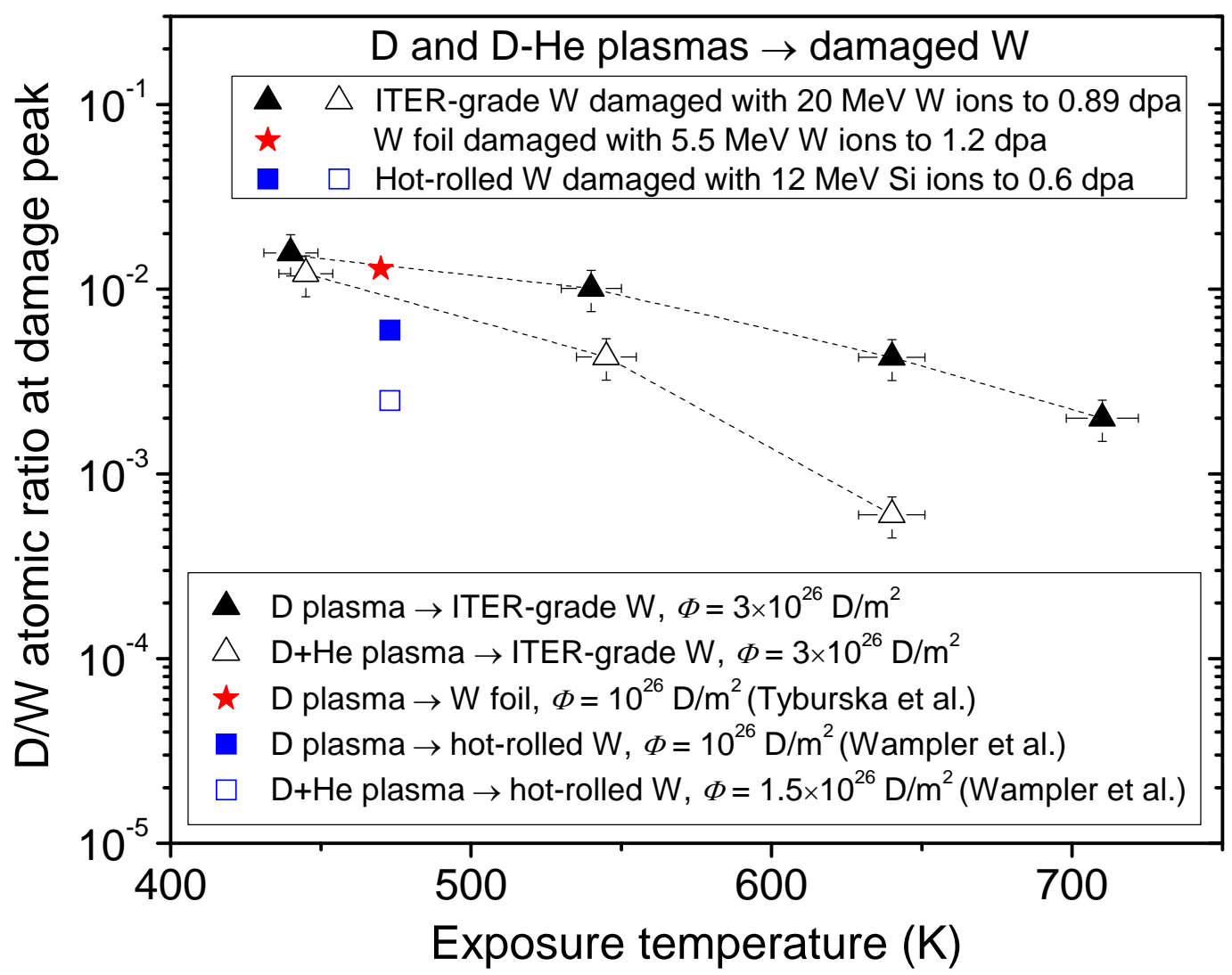

Figure 4. Deuterium concentration (in units of $\mathrm{D}$ to $\mathrm{W}$ atomic ratio) at a depth of the damage peak in damaged ITER-grade $\mathrm{W}$ exposed to pure D plasma $\left(76 \mathrm{eV} \mathrm{D}_{2}{ }^{+}\right)$and D-He plasma $\{76$ $\left.\mathrm{eV}\left(\mathrm{D}_{2}^{+}+10 \% \mathrm{He}^{+}\right)\right\}$, as a function of the exposure temperature. Additionally, data on the D concentration in damaged $\mathrm{W}$ foil exposed to pure $\mathrm{D}$ plasma $\left(76 \mathrm{eV} \mathrm{D}_{2}{ }^{+}\right.$) (Tyburska et al. [6]) and damaged hot-rolled $\mathrm{W}$ exposed to pure D plasma $\left(90 \mathrm{eV} \mathrm{D}{ }^{+}\right)$and $\mathrm{D}-\mathrm{He}$ plasma $\left\{90 \mathrm{eV}\left(\mathrm{D}^{+}+5 \%\right.\right.$ $\mathrm{He}^{+}$)\} (Wampler et al. [4]) are shown for a comparison. The displacement damage characteristics and applied D ion fluences, $\Phi$, are indicated in the legends. 


\section{References}

[1] V. Barabash, G. Federici, M. Rödig, L.L. Snead, C.H. Wu, J. Nucl. Mater. 283-287 (2000) 138.

[2] H. Iida, V. Khripunov, L. Petrizzi, G. Federici, ITER Nuclear Analysis Report G 73 DDD 2 W 0.2, 2004.

[3] M. Fukumoto, H. Kashiwagi, Y. Ohtsuka, Y. Ueda, M. Taniguchi, T. Inoue, K. Sakamoto, J. Yagyu, T. Arai, I. Takagi, T. Kawamura, J. Nucl. Mater. 390-391 (2009) 572.

[4] W.R. Wampler and R.P. Doerner, Nucl. Fusion 49 (2009) 115023.

[5] W.R. Wampler and R.P. Doerner, Phys. Scripra T138 (2009) 14037.

[6] B. Tyburska, V.Kh. Alimov, O.V. Ogorodnikova, K. Schmid, K. Ertl, J. Nucl. Mater. 395 (2009) 150.

[7] B. Tyburska, V.Kh. Alimov, O.V. Ogorodnikova, K. Ertl, K. Schmid, J. Roth, J. Nucl. Mater. (2010), doi:10.1016/j.jnucmat.2010.11.044

[8] O.V. Ogorodnikova, B. Tyburska, V.Kh. Alimov, K. Ertl, J. Nucl. Mater. (2011), doi:10.1016/j.jnucmat.2010.12.012.

[9] W.R. Wampler, D.L. Rudakov, J.G. Watkins, C.J. Lasnier, J. Nucl. Mater. (2010), doi: 10.1016/j.jnucmat.2010.11.043.

[10] M. Miyamoto, D. Nishijima, Y. Ueda, R.P. Doerner, H. Kurishita, M.J. Baldwin2, S. Morito, K. Ono, J. Hanna, Nucl. Fusion 49 (2009) 065035.

[11] V.Kh. Alimov, W.M. Shu, J. Roth, K. Sugiyama, S. Lindig, M. Balden, K. Isobe, T. Yamanishi, Phys. Scr. T138 (2009) 014048.

[12] O.V. Ogorodnikova, T. Schwarz-Selinger, K. Sugiyama, V.Kh. Alimov, J. Appl. Phys. 109 (2011) 013309.

[13] V.Kh. Alimov, B. Tyburska, O.V. Ogorodnikova, J. Roth, K. Isobe, T. Yamanishi, J. Nucl. Mater. (2010), doi:10.1016/j.jnucmat.2010.08.054.

[14] Y. Ueda, M. Fukumoto, J. Yoshida, Y. Ohtsuka, R. Akiyoshi, H. Iwakiri, N. Yoshida, J. Nucl. Mater. 386-388 (2009) 725. 
[15] Y. Ueda, H. Kashiwagi, M. Fukumoto, Y. Ohtsuka, N. Yoshida, Fusion Sci. Technol. 56 (2009) 85 .

[16] G. Kalinin, V. Barabash, S. Fabritsiev, H. Kawamura, I. Mazul, M. Ulrickson, C. Wu, S. Zinkle, Fusion Eng. Des. 55 (2001) 231.

[17] T. Hirai, G. Pintsuk, J. Linke, M. Batilliot, J. Nucl. Mater. 390-391 (2009) 751.

[18] V.Kh. Alimov, B. Tyburska-Püschel, S. Lindig, Y. Hatano, M. Balden, J. Roth, K. Isobe, M. Matsuyama, T. Yamanishi, J. Nucl. Mater. (submitted).

[19] http://srim.org.

[20] Standard Practice for Neutron Radiation Damage Simulation by Charge-Particle Irradiation, E521-96, Annual Book of ASTM Standards, Vol. 12.02, American Society for Testing and Materials, Philadelphia, 1996, p. 1.

[21] Q. Xu, T. Yoshiie, H.C. Huang, Nucl. Instr. and Meth. B 206 (2003) 123.

[22] G.-N. Luo, W.M. Shu, H. Nakamura, S. O’Hira, M. Nishi, Rev. Sci. Instrum. 75 (2004) 4374.

[23] V.Kh. Alimov, M. Mayer, J. Roth, Nucl. Instr. and Meth. B 234 (2005) 169.

[24] S. Lindig, M. Balden, V.Kh. Alimov, A. Manhard, C. Höschen, T. Höschen, B. TyburskaPüschel, J. Roth, Phys. Scr. (submitted).

[25] J.B. Condon and T. Schober, J. Nucl. Mater. 207 (1993) 1.

[26] A.A. Haasz, M. Poon, J. Davis, J. Nucl. Mater. 266-269 (1999) 520.

[27] V.Kh. Alimov, J. Roth, M. Mayer, J. Nucl. Mater. 337-339 (2005) 619.

[28] S. Lindig, M. Balden, V.Kh. Alimov, T. Yamanishi, W.M. Shu, J. Roth, Phys. Scr. T138 (2009) 014040.

[29] V.Kh. Alimov, W.M. Shu, J. Roth, S. Lindig, M. Balden, K. Isobe, T. Yamanishi, J. Nucl. Mater. (2011), doi: 10.1016/j.jnuclmat.2011.01.088.

[30] H. Iwakiri, K. Yasunaga, K. Morishita, N. Yoshida, J. Nucl. Mater. 283-287 (2000) 1134.

[31] M.J. Baldwin, R.P. Doerner, B. Wampler, D. Nishijima, T. Lynch, M. Miyamoto, Nucl. Fusion (accepted for publication).

[32] G.H. Kinchin, R.S. Pease, Rep. Prog. Phys. 18 (1955) 1. 
[33] A.F. Bobkov, V.T. Zabolotnyi, L.I. Ivanov, G.M. Kukavadze, N.A. Makhlin, A.L. Suvorov, Atomic Energy 48(5) (1980) 331. 